\title{
Evaluation of Body Discomfort Score of Agricultural Worker during Weeding Operation
}

\author{
Premkumari", Devanand Maski, M. Veerangouda and Sunil Shirwal \\ Department of Farm Machinery and Power Engineering, College of Agricultural \\ Engineering, University of Agricultural Sciences, Raichur, Karnataka, India \\ *Corresponding author
}

\section{A B S T R A C T}

\section{Keywords \\ Ergonomics, Postural discomfort, Human Drudgery, \\ Musculoskeletal \\ Disorders. Physiological Workload \\ Article Info \\ Accepted: 04 September 2018 Available Online: 10 October 2018}

\begin{abstract}
Weeding operation is a task demanding high labour and directly associated with human drudgery. The purpose of this study was to assess the level of human drudgery and musculoskeletal disorders of farm workers involved in weeding operation. This study was carried out in University of agricultural sciences, Raichur district of Karnataka State.Women play an important role in agriculture. Most of the weeding operation was done by women. To determine the discomfort level two different methods were used. These are overall discomfort rating method (ODR) and body part discomfort score (BPDS). The ODR during weeding with khurpi, CIAE wheel hoe and CAE weeder ranged from 6.5 to $7.2,6.5$ to 7.2 and 4.9 to 5.6 respectively. The BPDS during weeding ranged from 56 to 70,59 to 64 and 52 to 63 for khurpi, CIAE wheel hoe and CAE weeder respectively.
\end{abstract}

\section{Introduction}

Women in rural India play a major role in shaping the country's economy through their active participation in agriculture. At present, women work force in agriculture and allied sector is estimated at about 61 million which amounts to about $30 \%$ of the total rural workers in the country. Woman is the backbone of agricultural workforce but worldwide her hard work has mostly been unpaid. She does the most tedious and backbreaking tasks in agriculture.

Agriculture ranks among the most hazardous industries. The physical demand of the farm work which range from moderate to heavy, often include standing, squatting, bending and reaching, carrying heavy loads and working for long hours, may cause certain hazards to the person. Thus the health of agricultural worker is always at risk.

Weed control in Indian farm is a serious concern. Weeds pose major problem during warm and humid climate especially affecting kharif crops. The problem of weed control is more acute in black soil during kharif season. Weed control is one of the most expensive operations in crop growth. Weeding is one of the maximum drudgery involved activity performed for highest number of days in a 
year. These women do the back breaking agricultural activities without any protections from sun, soil or shower with the traditional tools. To increase the productivity of the women's work there is a greater need for the ergonomic analysis of the activities performed by women and to study the circulatory stress and the physiological cost of each agricultural activity (Hasalkar, 2004). Hand tools and manually operated equipments are extensively used for digging, weeding and harvesting operations in agriculture. Weeding is one of the most important farm operations in crop production system. The most commonly used hand tools and equipments by the farmers for manual operations are spade, weeder, thresher, sprayer, plough, sickle, paddy puller, straw puller, hoe, hand power tiller etc., Manual weeding requires a huge labour force and accounts for about 25 per cent of the total labour requirement (Nag and Datt, 1979). So manually operated weeders are remained first priority of the researchers.

Discomfort is the body pain arising as a result of the working posture and for an excessive stress on muscles due to the effort involved in the activities. It is also called overall discomfort. In many of the agricultural operations, though the work may be within physiological limits, the body discomfort restrict the duration of work depending upon the static loading component involved in it. Drudgery caused due to bad posture is reflected in terms of postural discomfort experienced by the worker. It has been observed by Gite (1996) that muscular discomfort of body is comparatively more important than heart rate and oxygen consumption rate in agricultural operations as limiting factors. For assessment of body discomfort various subjective rating scale has been developed but the methods which are commonly followed are Borg (1982), Corllet and Bishop (1976) visual analog discomfort (VAD).
The aim of this study was to evaluate the overall discomfort rate and body discomfort score of agricultural worker during weeding operation in fields of university of agricultural sciences campus Raichur.

\section{Materials and Methods}

The study was carried out on farm women workers in age group 25-45 years were randomly chosen. Thirty body dimensions including strength parameters involved in manual weeding operations of 10 female $\left(S_{1}\right.$ to $S_{10}$ ) of UAS Campus Raichur were measured by using anthropometric kit and mean values of body dimensions and strength parameters of the subjects were calculated. They were screened for normal health with medical investigations. These subjects were used in the field trials for manual weeding each subject was replicated three times. Evaluated the performance of the three types of manual weeder viz., Khurpi (Traditional), Wheel hand hoe (CIAE model), Standing khurpi (CAE model) for ODR and BPDS.

In the present study two methods i.e., overall discomfort rating (ODR) and body part discomfort score (BPDS) were selected to assess the body discomfort. The overall discomfort rate and body parts discomfort score were obtained by the method/technique suggested by Corlett and Bishop (1976). This technique was used by Gite (1991), Gite (1996), Kathirvel et al., (2003), etc. The overall discomfort rating was obtained with a ten point physiological rating scale $(0=$ no discomfort, 10 = extreme discomfort). For this purpose a scale of about $70 \mathrm{~cm}$ length was fabricated having 0 to 10 digits marked on it at equidistant.

A movable pointer was provided to indicate the rating show in Figure 1. For BPDS Corllet and Bishop have suggested body map showing its 27 regions as shown in Figure 2. 
Field experiments were carried out to evaluate the performance of weeding operation in terms of ODR and BPDS. The selected ten female subjects were participated in the operation.

\section{Measuring discomfort}

The selected female subjects were asked to report on the field in the morning at $8 \mathrm{am}$. It was ensured that they were in good health, had sound sleep in the previous night, and had a normal breakfast. They were free from stimulated beverages, tobacco and recent exercises. The subjects were explained about the objectives of the experiment and made familiar with the operation to ensure their full cooperation. The environmental temperature and relative humidity were measured with the help of thermometer and hygrometer, respectively.

\section{Overall discomfort rating}

The subject was asked to perform weeding operation with khurpi, the duration of each trial was one hour. During the one hour operation, the subject was not given any rest. After the weeding operation with khurpi data an overall discomfort rating and body parts discomfort score was recorded. At the end of each trial, subject was asked to indicate their overall discomfort rating on the scale. The overall discomfort rating given by each subject were added and averaged to get the mean rating.

\section{Body part discomfort score}

For evaluating BPDS, the subject was asked to mention all body parts with discomfort, starting with most painful, the next most painful and so on till no further areas were referred (plate 1). The subject was asked to point out on the body part in the order of one point for maximum pain, two points for next maximum pain, and so on. The number of different groups of body parts, which are identified from extreme discomfort to no discomfort, represented the number of intensity levels of pain experienced. The maximum number of intensity levels of pain experienced under different treatment was six categories. The rating was assigned to these categories in an arithmetic order viz., $1^{\text {st }}$ category (body parts experiencing maximum pain) rating was allotted as ' 6 ' and for $2^{\text {nd }}$ category (body parts experiencing next maximum pain) rating was allotted ' 5 ' and so on, finally for the sixth category (body parts experiencing least pain) rating was allotted as ' 1 '.

It was found that the number of intensity levels of pain experienced by different subjects might vary. In order to get an ideal analysis of the results after ranking, each data was marked in a numerical way. All the marks were added for each body part. The body discomfort score of all the subjects was added. The procedure repeated for the next 9 subjects for khurpi and for remaining two methods of weeding operations.

\section{Results and Discussion}

Thirty body dimensions including strength parameters involved in manual weeding operations of 10 female $\left(S_{1}\right.$ to $\left.S_{10}\right)$ of UAS Campus Raichur were measured. The consolidated data on selected body dimensions and strength parameters are presented in Table 1 .

\section{Assessment of body discomfort of the operator during manual weeding operations}

Field experiments were carried out to assess overall discomfort rating (ODR) and body part discomfort score (BPDS) experienced by the selected subjects for manual weeding operations. 
Fig.1 Overall discomfort rating scale

Extremely

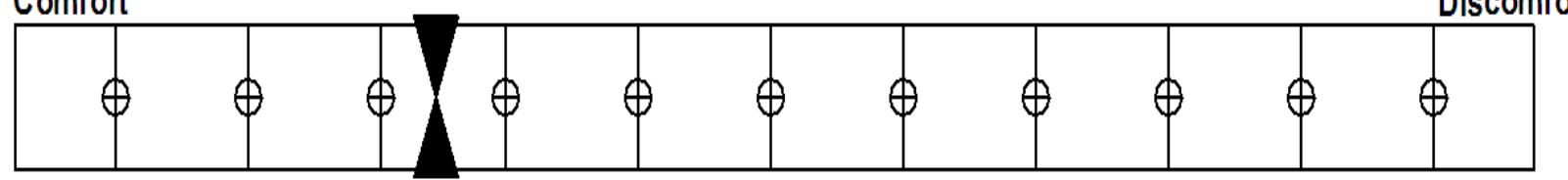

Fig.2 Different body regions for evaluation of body part discomfort score

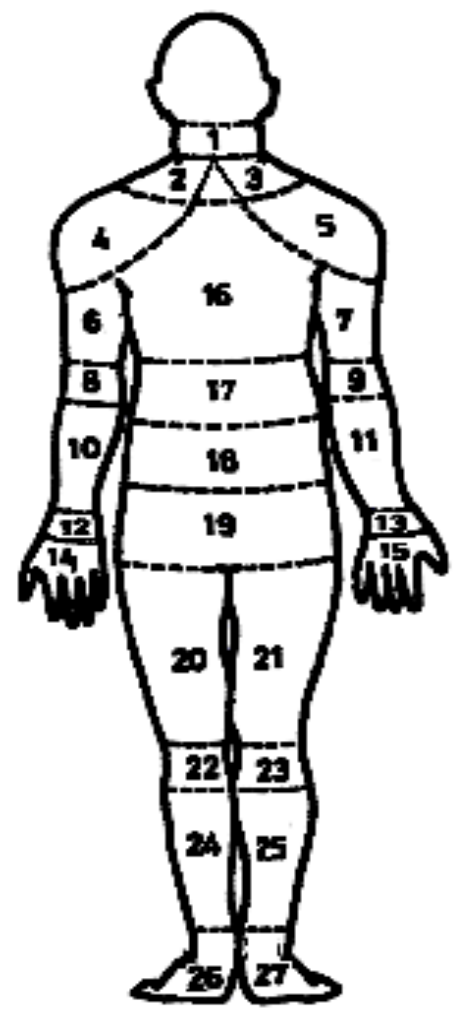

1. Neck

2. Clavicle Left

3. Clavicle Right

4. Left Shoulder

5. Right Shoulder

6. Left Arm

7. Right Arm

8. Left Elbow

9. Right Elbow

10. Left Fore Arm

11. Right Fore Arm

12. Left Wrist

13. Right Wrist

14. Left Palm

15. Right Palm

16. Upper Back

17. Mid Back

18. Lower Back

19. Buttocks

20. Left Thigh

21. Right Thigh

22. Left Knee

23. Right Knee

24. Left Leg

25. Right Leg

26. Left Foot

27. Right Foot 
Fig.3 Overall discomfort rate in manual weeding operation

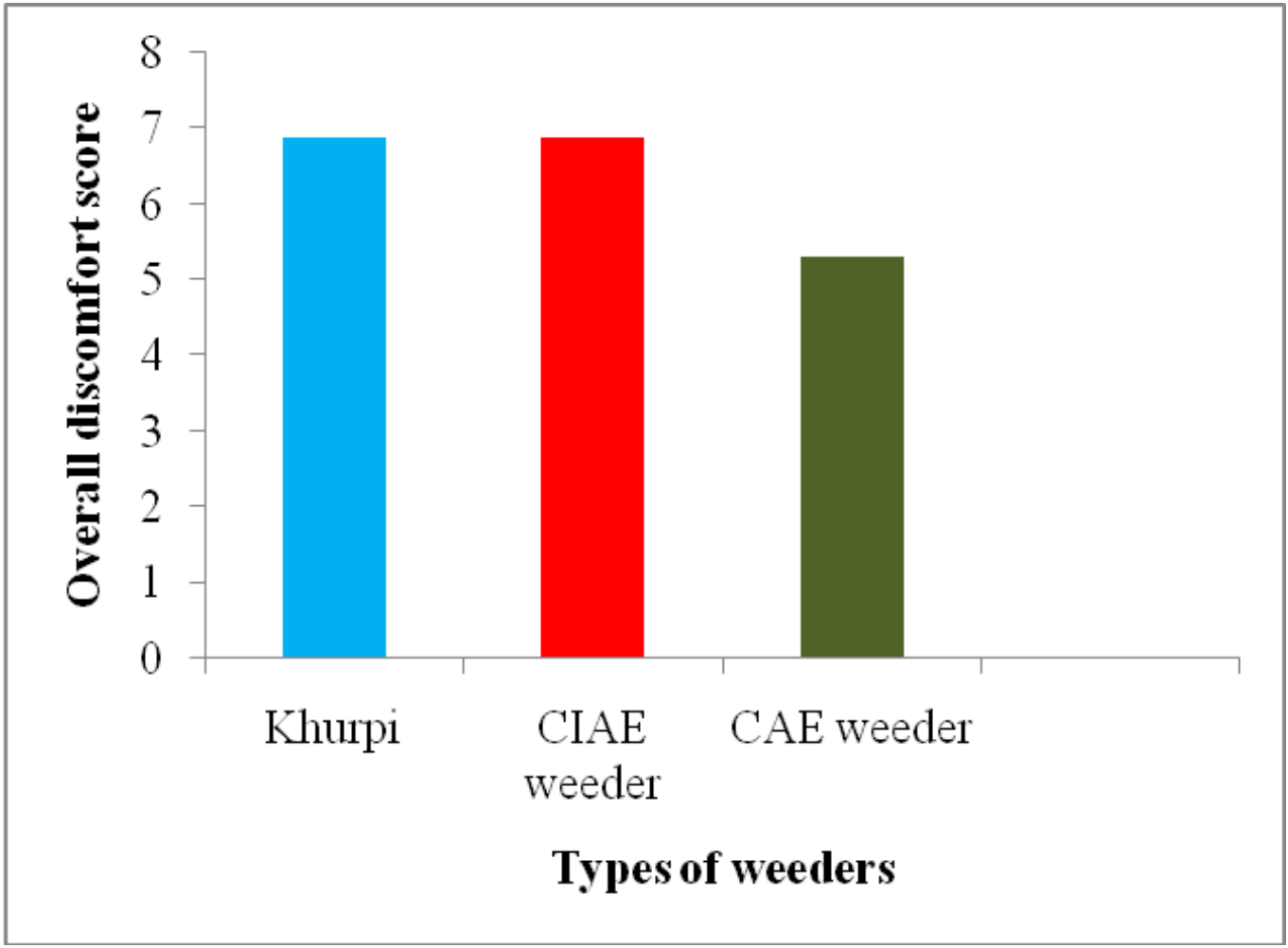

Fig.4 Body parts discomfort score in manual weeding operation

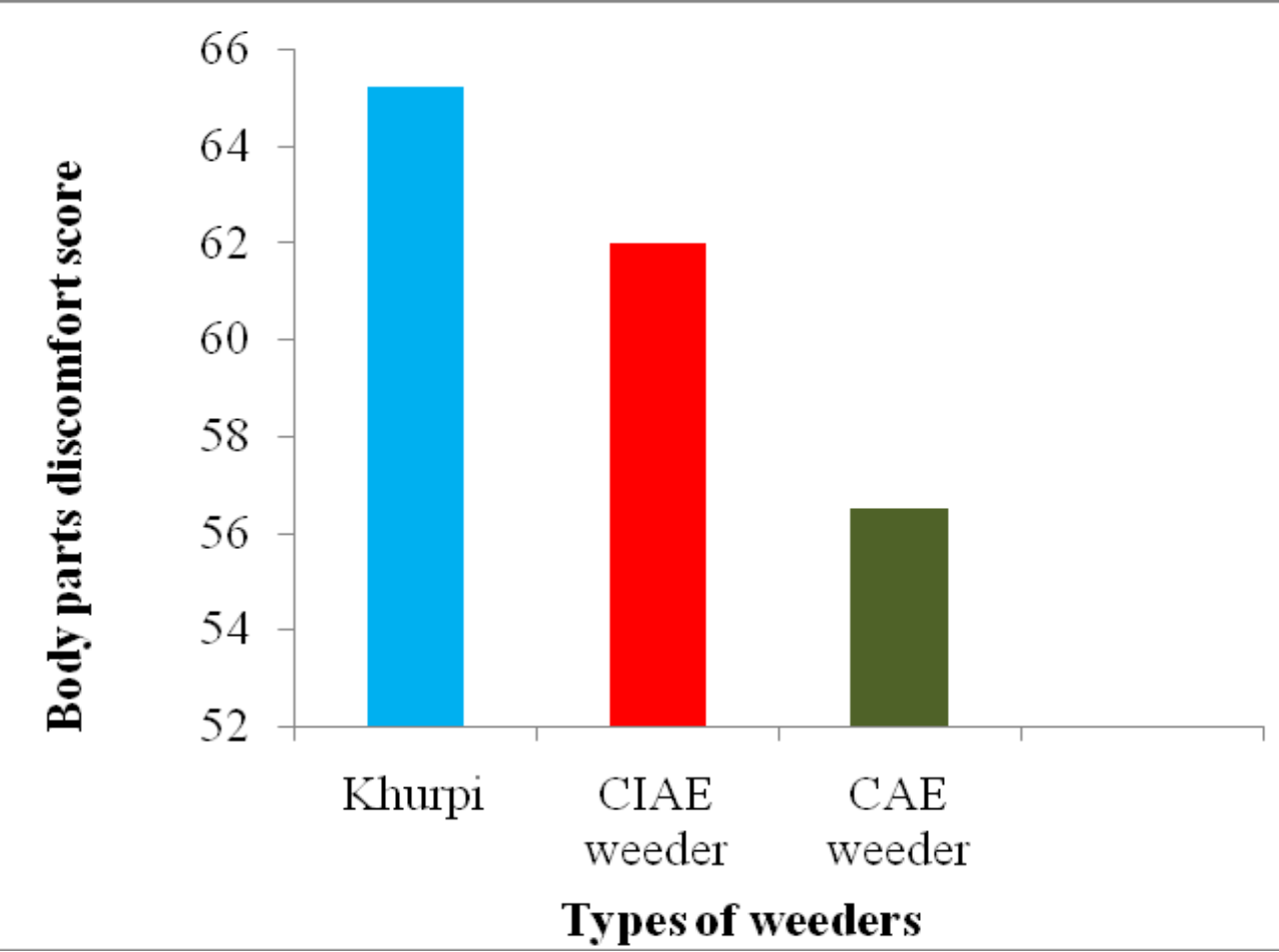


Table.1 Anthropometric and strength measurements of 10 randomly selected female agricultural workers of age group of 25-45 years

\begin{tabular}{|c|c|c|c|c|c|c|c|c|c|c|c|}
\hline Body Dimensions & $\mathbf{S}_{1}$ & $\mathbf{S}_{\mathbf{2}}$ & $\mathbf{S}_{\mathbf{3}}$ & $\mathbf{S}_{4}$ & $\mathbf{S}_{5}$ & $S_{6}$ & $\mathbf{S}_{7}$ & $\mathbf{S}_{8}$ & $\mathbf{S}_{9}$ & $S_{10}$ & Mean \\
\hline \multicolumn{12}{|c|}{ A. Measurements in standing posture } \\
\hline Weight (Kg) & 58 & 60 & 50 & 44 & 57 & 47 & 45 & 66 & 54 & 45 & 52.6 \\
\hline Stature & 161 & 138 & 152 & 157 & 148 & 151.5 & 142 & 151 & 149 & 159 & 150.85 \\
\hline Eye height & 147 & 127 & 136 & 142 & 140 & 142 & 132 & 141 & 133 & 144 & 138.4 \\
\hline Shoulder height & 137 & 116 & 126 & 131 & 122 & 129 & 119 & 125 & 122 & 132 & 125.9 \\
\hline Elbow height & 102 & 87 & 96 & 97 & 90 & 97 & 86 & 91 & 91 & 98 & 93.5 \\
\hline Olecranon height & 103 & 90 & 94 & 91 & 93 & 96 & 87 & 95 & 92 & 96 & 93.7 \\
\hline Waist height & 105 & 86 & 93 & 94 & 95 & 98 & 90 & 93 & 90 & 100 & 94.4 \\
\hline Knee height & 48 & 43 & 44 & 42 & 44 & 40 & 43 & 43 & 37 & 47 & 43.1 \\
\hline Arm reach from the wall & 85 & 80 & 68 & 94 & 84 & 86 & 79 & 79 & 75 & 93 & 82.3 \\
\hline Forearm hand length & 43.5 & 39 & 40 & 38 & 41 & 43 & 39 & 41 & 38 & 44 & 40.65 \\
\hline Span & 163.5 & 144 & 153 & 148 & 153 & 156 & 149 & 151 & 137 & 161 & 151.55 \\
\hline Span akimbo & 83 & 77 & 74 & 76 & 76 & 78 & 76 & 79 & 74 & 78 & 77.1 \\
\hline Thumb tip reach & 68 & 61 & 62 & 65 & 61 & 67.5 & 68 & 71 & 62 & 75 & 66.05 \\
\hline Shoulder grip length & 66 & 55 & 69 & 52 & 61 & 63 & 63 & 61 & 55 & 68 & 61.3 \\
\hline \multicolumn{12}{|c|}{ B. Measurements in sitting posture } \\
\hline Sitting height & 77 & 70 & 76 & 73 & 73 & 72 & 82 & 84 & 75 & 89 & 77.1 \\
\hline Eye height & 68 & 60 & 64 & 66 & 66 & 64 & 68 & 70 & 69 & 69 & 66.4 \\
\hline Popliteal height & 41 & 41 & 39 & 42 & 37 & 47 & 45 & 42 & 39 & 44 & 41.7 \\
\hline Elbow rest height & 21 & 21 & 19 & 20 & 21 & 22 & 18 & 23 & 20 & 23 & 20.8 \\
\hline \multicolumn{12}{|c|}{ C. Miscellaneous measurements } \\
\hline Hand length & 17.5 & 17 & 16 & 17 & 16 & 17.5 & 16.5 & 17 & 16 & 17 & 16.75 \\
\hline Hand breadth & 8 & 9 & 10 & 9 & 9 & 9 & 9 & 9 & 8.5 & 9 & 8.95 \\
\hline Palm length & 10 & 10 & 8.5 & 9 & 9.5 & 10 & 9.5 & 10 & 9 & 10 & 9.55 \\
\hline Grip diameter (inside) & 4.35 & 4.054 & 3.33 & 3.484 & 3.55 & 3.696 & 3.715 & 3.269 & 3.28 & 3.806 & 3.33 \\
\hline Grip span & 8.5 & 10.5 & 13 & 11 & 9 & 11 & 8.5 & 13 & 12 & 10 & 10.65 \\
\hline Maximum grip length & 12 & 10.3 & 12.5 & 13.4 & 14.5 & 14 & 14 & 13 & 12.5 & 13 & 12.92 \\
\hline \multicolumn{12}{|c|}{ D. Strength Measurements } \\
\hline Hand grip strength (right) (N) & 170.69 & 183.45 & 215.82 & 157.94 & 110.85 & 136.36 & 130.47 & 133.42 & 80.44 & 130.47 & 144.99 \\
\hline Hand grip strength (left)(N) & 206.01 & 147.98 & 166.77 & 127.53 & 119.68 & 128.51 & 143.23 & 180.50 & 74.56 & 89.27 & 138.42 \\
\hline Push strength with both hands in standing posture (N) & 348.26 & 241.33 & 313.92 & 225.63 & 185.41 & 180.50 & 271.74 & 271.74 & 157.94 & 137.34 & 233.38 \\
\hline Pull strength with both hands in standing posture $(\mathbf{N})$ & 315.88 & 193.26 & 255.06 & 206.01 & 185.41 & 70.63 & 258.00 & 258.00 & 114.78 & 185.41 & 204.24 \\
\hline Right hand pull strength in sitting posture (N) & 187.37 & 120.66 & 138.32 & 138.32 & 157.94 & 98.1 & 138.32 & 184.43 & 93.20 & 140.28 & 139.69 \\
\hline Left hand pull strength in sitting posture (N) & 189.33 & 100.06 & 129.49 & 126.55 & 147.15 & 78.48 & 136.36 & 171.68 & 81.42 & 151.07 & 131.16 \\
\hline
\end{tabular}

All dimensions are in $\mathrm{cm}$, unless specified. 
Table.2 Mean body parts discomfort score during manual weeding

\begin{tabular}{|c|c|c|c|c|c|c|}
\hline \multirow{2}{*}{$\begin{array}{l}\text { Methods } \\
\text { of } \\
\text { Weeding }\end{array}$} & \multicolumn{3}{|c|}{ Overall Discomfort Rating } & \multicolumn{3}{|c|}{ Body Parts Discomfort Score } \\
\hline & Khurpi & $\begin{array}{c}\text { CIAE } \\
\text { Wheel hoe }\end{array}$ & $\begin{array}{c}\text { CAE } \\
\text { Weeder }\end{array}$ & Khurpi & $\begin{array}{c}\text { CIAE } \\
\text { wheel hoe }\end{array}$ & $\begin{array}{c}\text { CAE } \\
\text { weeder }\end{array}$ \\
\hline \multicolumn{7}{|l|}{ Subjects } \\
\hline $\mathbf{S}_{1}$ & 6.7 & 7.1 & 5.6 & 69 & 62 & 63 \\
\hline $\mathbf{S}_{2}$ & 6.6 & 7 & 5.3 & 66 & 59 & 55 \\
\hline $\mathbf{S}_{3}$ & 6.9 & 6.9 & 5.4 & 65 & 63 & 60 \\
\hline $\mathbf{S}_{4}$ & 7.2 & 6.7 & 4.9 & 67 & 64 & 57 \\
\hline $\mathbf{S}_{5}$ & 6.9 & 7 & 5 & 63 & 61 & 55 \\
\hline$S_{6}$ & 6.5 & 7.1 & 5.1 & 64 & 62 & 54 \\
\hline $\mathbf{S}_{7}$ & 7.2 & 6.5 & 5.6 & 70 & 61 & 57 \\
\hline $\mathbf{S}_{8}$ & 7.1 & 6.6 & 5.4 & 69 & 64 & 52 \\
\hline $\mathbf{S}_{9}$ & 6.7 & 6.7 & 5.5 & 56 & 63 & 56 \\
\hline$S_{10}$ & 7.1 & 7.2 & 5.2 & 63 & 61 & 56 \\
\hline Mean & 6.89 & 6.88 & 5.3 & 65.2 & 62 & 56.5 \\
\hline
\end{tabular}

Plate.1 Evaluation of body part discomfort score

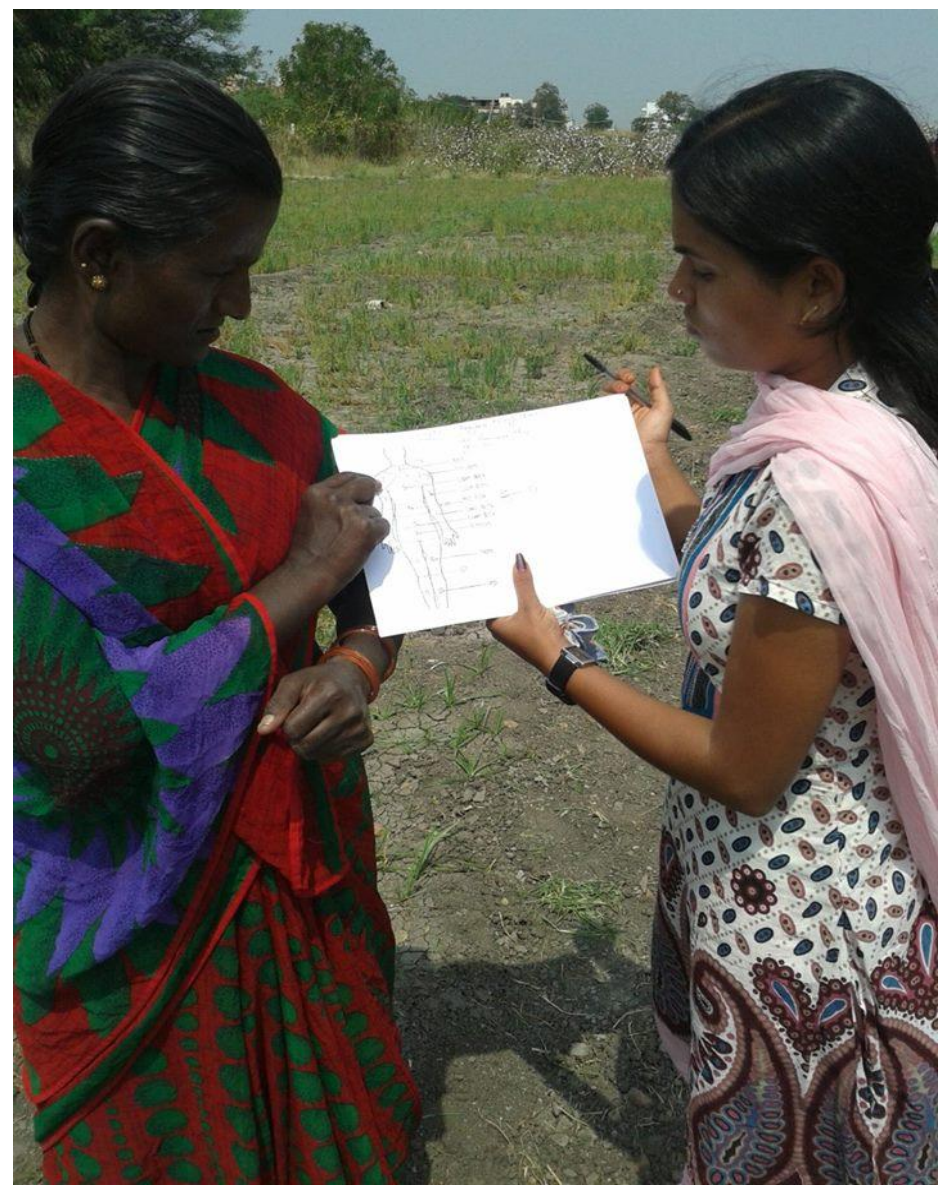




\section{Overall discomfort rate (ODR)}

ODR experienced by the selected subjects during weeding operation in linseed crop is presented in Table 2. The ODR for subjects during weeding with khurpi ranged from 6.5 to 7.2. The ODR for subjects during weeding with CIAE wheel hoe and CAE weeder ranged from 6.5 to 7.2 and 4.9 to 5.6 respectively. Maximum ODR was observed in khurpi method followed by CIAE wheel hoe and CAE weeder.

The ODR value for khurpi and CIAE wheel hoe were nearly same. CAE weeder was less fatigue to perform weeding operation as compared to khurpi and CIAE wheel hoe.

The mean ODR of subjects during weeding with khrupi, CIAE wheel hoe and CAE weeder were $6.89,6.88$ and 5.3 respectively shown in Figure 3.

\section{Body part discomfort Score (BPDS)}

Experiments were carried out in order to assess BPDS of subjects during manual weeding operation. The BPDS during weeding with all three methods are presented in Table 2.

BPDS experienced by the selected subjects during weeding operation in linseed crop are presented in Table 2. The BPDS for subjects during weeding with khurpi ranged from 56 to 70. The BPDS for subjects during weeding with CIAE and CAE weeder ranged from 59 to 64 and 52 to 63 respectively. Maximum BPDS was observed in khurpi followed by CIAE wheel hoe and CAE weeder. The BPDS value for CAE weeder and CIAE wheel hoe were nearly same. CAE weeder was less fatigue to perform weeding operation as compared to khurpi and CIAE wheel hoe but area covered was less compared to other methods.

The mean BPDS of subjects during weeding with khrupi, CIAE wheel hoe and CAE weeder were, $65.2,62$ and 56.5 respectively shown in Figure 4.
The majority of discomfort was observed at left shoulder, right shoulder, left arm, right arm, upper back, lower back right thigh and left thigh for all the subjects while weeding with khurpi. This was because of squatting posture and use of wrist during the operation. Whereas, the majority of discomfort was observed at right shoulder, left shoulder, left arm, right arm, upper back, clavicle left and clavicle right for all the subjects for both CIAE wheel hoe and CAE weeder. This may be due to the higher speed of the operation during push and pull action to remove weeds and lateral-bending posture to maintain the implements in desired position.

In conclusion that ODR and BPDS clearly indicated that the $\mathrm{CAE}$ weeder is best for agricultural workers for weeding operation which reduces the physical discomfort. The ODR and BPDS for khurpi, CIAE wheel hoe and CAE weeder were 6.89, 6.88, 5.3 and 65.2, $62,56.5$ respectively. Weeder developed by CAE decrease the postural discomfort. CAE weeder was easy to operate by agriculture worker which was comfort and give higher weeding efficiency.

\section{References}

Ananthakrishnan, D. and Kathirvel, K., 2000, Ergonomic evaluation of hand tools. All India coordinated research project on human engineering and safety in agriculture. Progress report, pp: 118-149.

Badiger, C., Hasalkar, S. and Huilgol, S., 2004, Drudgery of farm women in agriculture and animal husbandry operations. kar. J. Agric. Sci., 17(4): 787-790.

Behera, B. K., Swain, S. and Mohanty, S. K., 2007, Ergonomic evaluation of push-pull type weeders with women operators. $J$. Agril. Engg., 44: 39-43.

Borah, R., Kalita, M. and Bhuyan, B. L., 2001, Ergonomical evaluation of drudgery prone farm activity - uprooting of seedlings. Humanizing work and work envir., 140-144. 
Borg, G., 1982, Subjective aspects of physical and mental load. Ergonomics, 21: 215220.

Corlett, E.N and Bishop, R.P., 1976, A technique for assessing postural discomfort. Ergonomics 19: 175-182.

Dewangan, K. N., Owary, C., Gogoi, G. and Gorate, D. U., 2007, Ergonomic evaluation of sickles for paddy harvesting by female agricultural workers. Paper presented at Int. Ergonomics Conf. on Humanizing Work and Work Envir., CIAE, Bhopal, December 10-12, pp: 6771.

Gite, L. P. and Majumder, J., 2007, Anthropometric and strength data bank of Indian agricultural workers. Paper presented at Int. Ergonomics Conf. on Humanizing Work and Work Envir., CIAE, Bhopal, December 10-12, pp: 8891.

Gite, L. P. and Yadav, B. G. 1989, Anthropometric survey of agricultural design: a case study. Appli. Erg., 20: 191196.

Gite, L. P., 1996, Some investigations on aside lever operated sprayer knapsack sprayer from mechanical and ergonomical considerations. Unpublished Ph.D Thesis.

Gites, L.P., 1991, Optimum handle height for animal-drawn mould board plough. Appli. Erg., 22: 21-28.

Hasalkar, S. M., Shivalli, R. C., Budihal, R. Y. and Biradar, N. P., 2004, Assessment of work load of weeding activity in crop production through heart rate. J. Human Ergology, 14: 165-167.
Kathirvel, K., Vidhu, K.P., Manian, R. and Senthilkumar, T., 2003, Ergonomic evaluation of direct paddy seeder. Thityseventh Indain Soc. of Agril. Engg. Conv., Udaipur FMP- HE. 2: 309-315.

Khogare, D. T. and Borkar, S., 2012a, Ergonomical evaluation of manually operated weeder. Electronic Int. Interdisciplinary Res. J., 42: 56-59.

Khogare, D. T. and Borkar, S., 2012b, Correlative study on postural discomfort and field performance evaluation of weeder. 2(1), Golden Research thoughts.

Nag, A., Nag, P. K. and Desai, H., 2003, Hand anthropometry of Indian women Indian.J Med Res 117, pp: 260-269.

Nag, P. K. and Dutt, P., 1979, Effectiveness of some simple agricultural weeders with reference to physiological responses. $J$. Hum. Ecol. 8: 13-21.

Philip, G. S. and Tewari, V. K., 2000, Anthropometry of Indian agricultural workers and implication on tool design. AMA., 31: 63-66.

Vyavahare, R. T. and Kallurkar, S. P, 2012, Anthropometric and strength data of Indian agricultural workers for equipment design: a review. Agric. Engg. Int., 14(4): 102-114.

Yadav, R and Pund, S., 2007, Development and Ergonomic Evaluation of Manual Weeder. Agril. Engg. Int., 9:11-18.

Yadav, R., Pund, S. R., Savani, J. B. and Gite, L. P., 2003, Anthropometric and physiological studies of agricultural workers of Gujarat. Proceeding 37 Convention of ISAE, pp: 24-32.

\section{How to cite this article:}

Premkumari, Devanand Maski, M. Veerangouda and Sunil Shirwal. 2018. Evaluation of Body Discomfort Score of Agricultural Worker during Weeding Operation. Int.J.Curr.Microbiol.App.Sci. 7(10): 365-373. doi: https://doi.org/10.20546/ijcmas.2018.710.039 